CARDOSO JC. 2014. Publicação em cultivo in vitro de plantas: qualidade para o avanço científico e tecnológico. Horticultura Brasileira 32: 383-384. DOI - http://dx.doi.org/10.1590/S0102-053620140000400002

\title{
Publicação em cultivo in vitro de plantas: qualidade para o avanço científico e tecnológico
}

\section{Jean C Cardoso}

UFSCar-CCA, Depto. Desenvolvimento Rural; C. Postal 153, 13600-970 Araras-SP; jeancardosctv@gmail.com

\section{RESUMO}

O cultivo in vitro de plantas tornou-se nas últimas décadas essencial a diferentes áreas do conhecimento, tais como a propagação em larga escala de espécies frutíferas e de plantas ornamentais, onde auxilia na produção de mudas de alta qualidade fitossanitária; como ferramenta em programas de melhoramento genético de espécies da horticultura; em estudos sobre fisiologia de plantas em condições controladas, bem como tem sido utilizado para a conservação de espécies ameaçadas de extinção. Dada essa importância e a necessidade de se realizar pesquisas e gerar artigos científicos de melhor qualidade nessa área do conhecimento, o objetivo do presente trabalho é apresentar alguns itens fundamentais a serem observados por autores, revisores e editores para o planejamento e elaboração de artigos científicos na área de cultivo in vitro de plantas, visando a sua posterior publicação e consequente reconhecimento. É importante que sejam produzidos bons artigos, cujos resultados contribuam para o avanço científico nessa área do conhecimento, que tenham alta reprodutibilidade, que possam ser fonte para outros artigos ou que resultem em novas tecnologias.

Palavras-chave: cultura de tecidos de plantas, artigo científico, redação científica, normas, formatação.

\begin{abstract}
Publication on in vitro plant growth: quality for scientific and technological advances

Over the past decades, in vitro plant growth has been essential for different fields of plant science, as the large scale propagation of plantlets for fruit and ornamental plants, the production of diseasefree plantlets, as tool for genetic breeding programs in horticulture, research about plant physiology under controlled environmental conditions, as well as, the use of in vitro techniques for conservation of endangered plant species. Due this importance and the necessity to develop research and scientific papers with high quality in this field, the aim of the present paper is to point out some fundamental items that support authors, reviewers and editors to the planning and preparation of papers in plant tissue culture, providing papers that will be published and recognized. Publication of high quality papers is important, whose results contributing to increase the scientific and technological advances in this field, with high reproducibility of data, and finally, with the possibility to be used in another research or as technological advance.
\end{abstract}

Keywords: plant tissue culture, scientific paper, scientific writting, standards, formatting.

(Recebido para publicação em 27 de junho de 2014; aceito em 5 de setembro de 2014)

(Received on June 27, 2014; accepted on September 5, 2014)

$\mathrm{O}$ cultivo in vitro é atualmente parte integrante de muitos sistemas de produção de plantas hortícolas e, como ciência, é de grande importância para a compreensão de aspectos fisiológicos, genéticos e fitossanitários das plantas assim cultivadas. Outra característica do cultivo in vitro é a possibilidade direta de seu uso como tecnologia, ou seja, a sua utilização no desenvolvimento de novos protocolos de propagação e conservação de plantas, já que muitas espécies têm esse método como principal meio de propagação, com produção de mudas em larga escala pelas chamadas biofábricas. Associado a isso temos acompanhado uma mudança nos padrões de qualidade das revistas e dos artigos científicos relacionados ao tema, sejam esses nacionais ou internacionais, o que exige grande compromisso dos autores com a excelência dos trabalhos publicados e seus aspectos inovadores. A publicação de resultados parciais, a baixa reprodutibilidade dos resultados e o número de resultados com pouca contribuição para o avanço científico e tecnológico estão entre os principais problemas dos artigos publicados na área de cultivo in vitro de plantas. Isso tem gerado problemas que vão desde o crivo insuficiente na avaliação e revisão de artigos, que muitas vezes chegam a ser publicados com informações incompletas ou mesmo imprecisas, diminuindo a confiabilidade dos resultados e sua reprodução, até a equivocada rejeição de trabalhos relacionados ao cultivo in vitro por algumas revistas brasileiras, que se confundem ao não aceitar trabalhos com qualidade e potencial para trazer inovações e contribuições científicas importantes.

A proposta desse trabalho é apresentar alguns padrões mínimos para autores, revisores e editores na área de cultivo in vitro de plantas, que eventualmente possam ser adotados como normas pelas revistas científicas brasileiras de ciências de plantas, para que tenhamos como resultado, artigos publicados com contribuição científica e tecnológica relevante e, portanto, com grande potencial de aplicação em nível nacional e internacional.

Como considerações gerais para a melhoria da qualidade dos trabalhos científicos que tratam do cultivo in vitro de plantas, sugerem-se diferentes pontos a serem considerados e que são 
descritos a seguir:

1) Os resultados obtidos e apresentados no trabalho devem trazer ao menos um aspecto inovador e não conterem apenas caráter confirmativo e repetições de estudos já excessivamente relatados; não devendo tampouco ser parciais e não conclusivos;

2) Os artigos devem ser apresentados completos, descrevendo em detalhes o genótipo utilizado, as condições de cultivo da planta matriz doadora dos explantes, o tipo de órgão/tecido utilizado, o método de assepsia (produtos e tempo de exposição), o tipo de explante usado, o método de regeneração dos explantes, além dos estádios de propagação ou multiplicação, enraizamento, alongamento e aclimatização das mudas obtidas, mesmo que esses não sejam o principal foco da parte experimental do estudo. $\mathrm{O}$ artigo deve incluir ainda as informações sobre os meios de cultura utilizados, colocados em detalhes, e condições ambientais de cultivo em todas as fases, incluindo temperatura, tipo de lâmpada utilizada como fonte de luz, fotoperíodo e intensidade luminosa (em $\mu \mathrm{mol} / \mathrm{m}^{2} / \mathrm{s}$ ou lux) e as possíveis variações de condições ambientais utilizadas;

3) Nos casos em que as justificativas científicas sejam precisas e plausíveis, poderão ser aceitos trabalhos que descrevam parte do processo de micropropagação, como por exemplo, na cultura de células gaméticas, em que muitas vezes há a formação de calos de origem gamética, já considerados em si um avanço devido à dificuldade na sua obtenção, mas que não regeneraram em plantas, mesmo após algumas tentativas frustradas. Também, em estudos de grande fundamentação científica e que envolvam análises fisiológicas, genéticas, técnicas de melhoramento genético utilizando o cultivo in vitro, relações entre plantas e microrganismos e outros, desde que os estágios seguintes de micropropagação não sejam primordiais para o sucesso do uso da tecnologia desenvolvida;

4) O meio de cultura deve ser detalhadamente descrito, podendo ser utilizada a referência que o descreve [Ex: MS (Murashige \& Skoog, 1962)], seguido das alterações realizadas, mencionadas suas respectivas concentrações (Ex: $2 \%$ de sacarose, $100 \mathrm{mg} / \mathrm{L}$ de myo- -inositol, e geleificado com $0,7 \%$ de Ágar (Marca e Tipo);

5) No estádio de aclimatização, que deve obrigatoriamente estar descrito em todos os trabalhos que envolvam a propagação e conservação de plantas in vitro, excetuando-se os casos descritos no item 3, devem ser descritos o substrato utilizado para o cultivo das plantas, o tipo de infraestrutura utilizada (casa de vegetação, telado, estufa, etc.) e os recursos disponíveis (climatização, tipo de cobertura, telas de sombreamento, tipo e frequência da irrigação, etc.), bem como as características do ambiente, como a variação de temperatura, luminosidade (sombreamento, intensidade luminosa, fotoperíodo) e faixa de variação da umidade relativa do ar;

6) Nos experimentos que visem o desenvolvimento de protocolos de propagação de espécies, os dados obtidos dos estádios de multiplicação devem conter informações de ao menos três repicagens, enquanto os dados de enraizamento devem ser provenientes de ao menos uma repetição do experimento, melhorando a qualidade e a reprodutibilidade das médias obtidas, bem como sua análise por comparação;

7) Devem conter ao menos uma fotografia de qualidade, colorida (ao menos na versão digital do artigo), que demonstre a evolução do experimento até a aclimatização das plantas, destacando eventos importantes no processo de regeneração de tecidos, órgãos sob cultivo in vitro, análises microscópicas, morfologia das plantas obtidas, entre outras.

É recomendável ainda que, para explicar o evento ocorrido, sempre que necessário e possível, sejam utilizadas ferramentas como microscopia, citogenética, marcadores moleculares e outras que incrementem a fundamentação científica e contribuam para a explicação e discussão dos resultados do artigo.

Os trabalhos de aplicação tecnológica como o desenvolvimento de protocolos, novas tecnologias, equipamentos e produtos, também podem ser aceitos. Porém, sempre respeitando os requisitos acima sugeridos e igualmente importantes, demonstrando o potencial de avanço e a eficiência da técnica desenvolvida em relação às atualmente ou mais comumente utilizadas. Quando os protocolos são desenvolvidos para espécies comerciais, é essencial utilizar no mínimo dois genótipos ou cultivares. Assim, aumenta-se a segurança de que aquele protocolo de fato tem potencial para a propagação vegetativa da espécie em questão. Na produção comercial, essa é uma característica muito valiosa para propagação em escala. Muitos autores usam, por exemplo, o título 'Micropropagação de antúrio' utilizando somente um genótipo, como se esse fosse representante da espécie como um todo e desconsiderando as interações entre genótipos e condições in vitro de desenvolvimento. No entanto, também é possível publicar protocolos para genótipos comerciais considerados recalcitrantes ou novos genótipos comerciais lançados no mercado, podendo ser considerado o uso de um único genótipo, desde que o trabalho apresente novidade suficiente para a publicação e tenha fundamentação e qualidade cientifica ou tecnológica de interesse da revista.

O cultivo in vitro de plantas ainda é e continuará sendo durante algum tempo ferramenta de estudos científicos em condições controladas, assim como técnica útil para conservação de plantas, desenvolvimento de novas cultivares e propagação em larga escala. São grandes os desafios científicos e tecnológicos na obtenção de processos mais eficientes com redução de custos de produção, ampliação das áreas de conhecimento que utilizam essas técnicas como ferramenta de avaliação, além dos próprios avanços da biotecnologia que dependem de sistemas eficientes de obtenção de plantas por métodos de regeneração específicos. Além disso, muitos métodos ainda em estágio de pesquisa podem se tornar técnicas inovadoras e de grande aplicação comercial e na conservação das espécies, como a criopreservação, os métodos de obtenção da embriogênese somática e a tecnologia de produção de plantas duplo-haplóides. Nesse sentido, o cultivo in vitro de plantas é parte integrante da ciência e do desenvolvimento de novas tecnologias para a horticultura, sendo necessário que as pesquisas e os artigos publicados reflitam consistentemente esses avanços para assim alicerçar o desenvolvimento científico, tecnológico, econômico, social e ambiental da ciência de plantas. 